\title{
Lobaplatin in Prophylactic Hyperthermic Intraperitoneal Chemotherapy for Advanced Gastric Cancer: Safety and Efficacy Profiles
}

This article was published in the following Dove Press journal: Cancer Management and Research

Yuxin Zhong'
Jing Zhang
Xiaofeng Bai'
Yuemin Sun'
Hao Liu'
Shuai Ma'
Yang Li ID'
Wenzhe Kang'
Fuhai Ma'
Weikun Li'
Yantao Tian'
'Department of Pancreatic and Gastric
Surgery, National Cancer Center/
National Clinical Research Center for
Cancer/Cancer Hospital, Chinese
Academy of Medical Sciences and Peking
Union Medical College, Beijing I0002I,
People's Republic of China; ${ }^{2}$ Department
of Abdominal Surgery, Huanxing Cancer
Hospital, Chaoyang District, Beijing
I00I22, People's Republic of China

Objective: This study aims to evaluate the safety and efficacy of lobaplatin in prophylactic hyperthermic intraperitoneal chemotherapy (HIPEC) for advanced gastric cancer.

Methods: Advanced gastric cancer patients who underwent radical gastric resection and/or prophylactic HIPEC were systematically reviewed in our department from January 2016 to June 2017. All enrolled patients were grouped in either HIPEC or non-HIPEC groups. Clinical data were collected and analyzed.

Results: A total of 129 patients were enrolled with 61 cases in the HIPEC group and 68 in the non-HIPEC group. The two groups were well balanced in terms of clinical characteristics. In patients of the HIPEC group, three suffered leakage from the duodenal stump or anastomosis, one suffered abnormal bleeding and two were found to have abnormal routine blood tests; no significant difference in adverse events between groups, however, was noted $(p>0.05)$ and most patients recovered uneventfully. During follow-up, peritoneal recurrence was significantly less among HIPEC patients $(p=0.029)$, with only three suffering peritoneal recurrence, as compared to 12 non-HIPEC patients. In addition, the estimated illness-specific 3 -year disease-free survival rate was significantly higher in the HIPEC group as compared to the non-HIPEC group (89.4\% vs.73.9\%; $p=0.031)$.

Conclusion: Lobaplatin in prophylactic HIPEC is safe for advanced gastric cancer patients after treatment by radical resection and can effectively improve illness-specific 3-year disease-free survival.

Keywords: gastric cancer, hyperthermic intraperitoneal chemotherapy, lobaplatin, safety

\section{Introduction}

Gastric cancer (GC) is the second most common and third most deadly malignancy in China, according to a 2019 study by the National Cancer Center. ${ }^{1}$ Postoperative recurrence, especially in the form of intraperitoneal metastases, is the main cause of death. $^{2-4}$ Studies have reported that over $20 \%$ of gastric cancer patients suffer peritoneal metastases either prior to or at the time of surgery, and over $50 \%$ of patients suffering T3 and T4 disease suffer peritoneal metastases after radical resection, underscoring the poor prognosis of this condition. ${ }^{2-4}$ Prior studies have confirmed that cytoreductive surgery in addition to hyperthermic intraperitoneal chemotherapy (HIPEC) significantly improves the prognosis of patients suffering peritoneal gastric cancer metastases. ${ }^{5-7}$

Compared with cisplatin and carboplatin, lobaplatin, a third-generation alkylating antineoplastic agent, exhibits good water-solubility, a wide anticancer spectrum
Correspondence: Yantao Tian

Email tianyantao@cicams.ac.cn 
and high antitumor activity. Harstrick et $\mathrm{al}^{8}$ verified the effectiveness of lobaplatin on gastric cancer cell lines and also found that it markedly inhibited several cisplatinresistant cell lines. Lobaplatin was found to inhibit gastric cancer progression by promoting gastric cancer cell apoptosis. ${ }^{9,10}$ However, the safety and effectiveness of this therapy, especially when used in combination with HIPEC for the purposes of preventing peritoneal gastric cancer metastases, remains unclear. Here, we evaluate the safety and efficacy of lobaplatin in prophylactic HIPEC in the setting of advanced gastric cancer.

\section{Methods}

\section{Patients and Clinical Protocol}

The clinical data of gastric cancer patients who consecutively underwent radical surgery and prophylactic HIPEC from January 2016 to June 2017 at National Cancer Center and Huanxing Cancer Hospital were systematically reviewed. Study inclusion criteria were: (1) adenocarcinoma diagnosed by endoscopic biopsy; (2) T3 or T4 clinical stages, with or without lymph node metastases as determined based on preoperative imaging; (3) no history of distant metastases; (4) a history of radical resection; and (5) Karnofsky performance status $>50$. Exclusion criteria were: (1) age $<18$ or $>75$ years; (2) peripheral blood leukocyte count $<3500 / \mathrm{mm}^{3}$ or platelet count $<80,000 /$ $\mathrm{mm} ;{ }^{3}$ or (3) serum bilirubin level $>3$ times the upper limit of normal (ULN), liver enzymes $>3$ times ULN or serum creatinine level $>1.5 \mathrm{mg} / \mathrm{dl}$. After fully explaining the benefits and disadvantages of HIPEC to patients and their families, patients chose whether to have HIPEC or not, and informed consent was accordingly signed. Our retrospective study protocol conformed to the ethical standards of the Declaration of Helsinki and was approved by the ethics committee at our institution (18-192/1770). This was a non-interventional retrospective study, so that patient consent to review their medical records was not required by the ethics committee.

All patients underwent the same preoperative examinations: electrocardiography, routine blood tests, hepatorenal function tests, serum carcinoembryonic antigen (CEA) level evaluation, in addition to imaging by endoscopic ultrasonography (EUS) as well as thoracic, abdominal and pelvic computed tomography (CT) imaging. Some patients underwent hepatic and pelvic magnetic resonance imaging (MRI) to exclude disease metastatic to the liver and pelvic cavity. The American Joint Committee on
Cancer (AJCC) staging system (7th edition) was applied for tumor staging. Clinical TNM stage was evaluated by two imaging specialists and endoscopic physicians who specialized in gastric cancer diagnosis based on CT and EUS findings. The standard clinical visual analog scale (VAS) was used for evaluating postoperative pain (ie, with 0 representing no pain and 10 representing the worst pain imaginable). All pathological specimens were also evaluated by two pathologists specializing in digestive diseases. General information, surgical data, clinical lab indices, complications, and follow-up outcomes were collected and recorded into our database.

\section{Surgery and HIPEC}

All patients routinely underwent laparoscopic-assisted radical gastrectomy, although sometimes it was necessary to convert to open surgery. The conventional five-hole method was adopted for laparoscopic surgery. After completion of the dissociation, an incision about $7 \mathrm{~cm}$ long in the middle of the upper abdomen was performed to remove the specimen and accomplish gastrointestinal anastomosis. Three different methods (Billroth I, Billroth II and Roux-en-Y) were used for gastrointestinal anastomoses. Patients who underwent Billroth II anastomosis were accepted the braun's anastomosis meanwhile. Prior to abdominal closure, four drains were placed. Left and right upper abdominal drains were placed in the pelvic cavity, a left lower abdomen drain was placed in the splenic fossa, and a right lower abdomen drain was placed in the lesser omental sac. For patient with non-HIPEC, 2 drains, one in the splenic fossa and one in the lesser omental sac, left after laparoscopic (mainly) gastrectomy. Both chief surgeons in our group had over 300 cases of prior experience in laparoscopic gastrectomy and completed procedures in this study based on unified consensus.

Patients who chose HIPEC underwent this treatment modality immediately postoperatively. Lobaplatin was dosed at $50 \mathrm{mg} / \mathrm{m}^{2}$ and dissolved in $3000 \mathrm{~mL} 5 \%$ intravenous glucose solution. The heated solution, maintained at $43^{\circ} \mathrm{C}$, was pumped into the peritoneal cavity at a rate of $500 \mathrm{~mL} / \mathrm{min}$ via left and right upper abdominal drainage tubes. The solution escaped the peritoneal cavity via left and right lower abdomen drainage tubes. Total HIPEC treatment time lasted $60 \mathrm{~min}$, and during this process, patients received oxygen inhalation and electrocardiographic monitoring. Patient vitals were observed by physicians at bedside. 


\section{Follow-Up}

The first postoperative day was defined as the beginning of follow-up. Patients were advised to visit their doctors every 3 months for the first 2 years, and then every 6 months for the next 3 years. The end of follow-up was set on July 31, 2019. The period from surgery to death or disease recurrence was defined as disease-free survival (DFS) and the period from surgery to death was defined as overall survival (OS).

\section{Statistical Analysis}

Data were analyzed using the Statistical Package for the Social Sciences (SPSS) version 24.0. Normally distributed quantitative data are presented as means \pm standard deviations and were analyzed using Student's $t$-test. Categorical data are presented as numbers and percentages; these data were analyzed using chi-squared or Fisher's exact tests. Ranked and abnormally distributed quantitative data were analyzed using the Mann-Whitney $U$-test. Survival analysis was calculated using the Kaplan-Meier method, and data were analyzed using the Log rank test. A $p$ value of less than 0.05 was considered to be the threshold for statistical significance.

\section{Results}

\section{Clinical Characteristics}

A total of 129 advanced gastric cancer patients consecutively seen in clinic were enrolled in this study, including $61(47.3 \%)$ patients in a HIPEC group and $68(52.7 \%)$ in a non-HIPEC group. Patients were well balanced in terms of gender, age, body mass index (BMI), American Society of Anesthesiologists (ASA) score, clinical cancer staging, surgical procedures, estimated blood loss, total operating time, and pathological tumor-node-metastasis (TNM) staging across the two groups (Table 1).

\section{Postoperative Recovery}

Most patients recovered well after surgery. The time to first flatus and time to first oral intake were similar between the two groups $(2.2 \pm 1.0$ vs $2.1 \pm 0.8$ days; 2.6 \pm 1.1 vs $2.4 \pm 1.0$ days, respectively) and were not statistically significant ( $p=0.529,0.389$; respectively). A total of three HIPEC patients suffered duodenal stump/anastomotic leakage, as did an additional three in the non-HIPEC group ( $p=1.000)$. No statistically significant differences in terms of blood loss, intestinal obstruction, abdominal infection, or incision infection were noted between two groups.
Table I Clinical Characteristics

\begin{tabular}{|c|c|c|c|}
\hline Variables & $\begin{array}{l}\text { HIPEC } \\
\text { Group } \\
(n=6 I)\end{array}$ & $\begin{array}{l}\text { Non-HIPEC } \\
\text { Group }(n=68)\end{array}$ & $p$ \\
\hline $\begin{array}{l}\text { Gender } \\
\text { Male } \\
\text { Female }\end{array}$ & $\begin{array}{l}32(52.5) \\
29(47.5)\end{array}$ & $\begin{array}{l}33(48.5) \\
35(51.5)\end{array}$ & 0.725 \\
\hline $\begin{array}{l}\text { Age (range, years) } \\
\text { BMI (range, kg/m²) }\end{array}$ & $\begin{array}{l}52.4 \pm 10.7 \\
(28-72) \\
23.7 \pm 2.2 \\
(18.75-27.76)\end{array}$ & $\begin{array}{l}53.1 \pm 10.5 \\
(25-70) \\
24.2 \pm 2.3 \\
(20.15-30.42)\end{array}$ & $\begin{array}{l}0.725 \\
0.206\end{array}$ \\
\hline $\begin{array}{l}\text { ASA score } \\
\qquad \begin{array}{l}1 \\
2 \\
3\end{array}\end{array}$ & $\begin{array}{l}25(41.0) \\
30(49.2) \\
6(9.8)\end{array}$ & $\begin{array}{l}27(39.7) \\
32(47.1) \\
9(13.2)\end{array}$ & 0.733 \\
\hline $\begin{array}{l}\text { Clinical T stage } \\
\text { T3 } \\
\text { T4 }\end{array}$ & $\begin{array}{l}37(60.7) \\
24(39.3)\end{array}$ & $\begin{array}{l}38(55.9) \\
30(44.1)\end{array}$ & 0.824 \\
\hline Clinical $\mathrm{N}$ positivity & $26(42.6)$ & $25(36.8)$ & 0.589 \\
\hline $\begin{array}{l}\text { Gastrectomy } \\
\text { Proximal } \\
\text { Distal } \\
\text { Total }\end{array}$ & $\begin{array}{l}10(16.4) \\
40(65.6) \\
11(18.0)\end{array}$ & $\begin{array}{l}14(20.6) \\
38(55.9) \\
16(23.5)\end{array}$ & 0.531 \\
\hline $\begin{array}{l}\text { Anastomotic } \\
\text { methods } \\
\text { Billroth I } \\
\text { Billroth II } \\
\text { Roux-en-Y }\end{array}$ & $\begin{array}{l}15(24.6) \\
25(41.0) \\
11(18.0)\end{array}$ & $\begin{array}{l}12(17.6) \\
26(38.2) \\
16(23.5)\end{array}$ & 0.550 \\
\hline $\begin{array}{l}\text { Estimated blood loss } \\
\text { (range; } \mathrm{mL} \text { ) } \\
\text { Overall operating } \\
\text { time (range; min) }\end{array}$ & $\begin{array}{l}105.6 \pm 37.5 \\
(50-220) \\
178.0 \pm 22.3 \\
(140-220)\end{array}$ & $\begin{array}{l}97.3 \pm 32.6 \\
(60-200) \\
171.8 \pm 18.5 \\
(130-240)\end{array}$ & $\begin{array}{l}0.180 \\
0.089\end{array}$ \\
\hline $\begin{array}{l}\text { Pathological TNM } \\
\text { stage } \\
\text { II } \\
\text { III }\end{array}$ & $\begin{array}{l}24(39.3) \\
37(60.7)\end{array}$ & $\begin{array}{l}30(44.1) \\
38(55.9)\end{array}$ & 0.585 \\
\hline
\end{tabular}

Notes: HIPEC, hyperthermic intraperitoneal chemotherapy; BMI, body mass index; ASA, American Society of Anesthesiologists; TNM, tumor-node-metastasis.

A total of two patients suffered peripheral blood leukocyte counts $<3500 / \mathrm{mm},{ }^{3}$ while none suffered abnormal liver function tests (serum bilirubin level $>3$ times or liver enzymes $>3$ times ULN) or abnormal renal function tests (serum creatinine level $>1.5 \mathrm{mg} / \mathrm{dl}$ ). The incidence of abnormalities in HIPEC patients was similar to that in nonHIPEC patients. No patients died during the perioperative period. Postoperative hospital stays were similar in both groups $(7.7 \pm 1.5$ vs $7.5 \pm 1.3$ days, $p=0.423)($ Table 2$)$. 
Table 2 Postoperative Recovery

\begin{tabular}{|c|c|c|c|}
\hline Variables & $\begin{array}{l}\text { HIPEC } \\
\text { Group } \\
(n=6 I)\end{array}$ & $\begin{array}{l}\text { No HIPEC } \\
\text { Group }(n=68)\end{array}$ & $p$ \\
\hline $\begin{array}{l}\text { Time to first flatus } \\
\text { (range; d) }\end{array}$ & $\begin{array}{l}2.2 \pm 1.0 \\
(1.2-8)\end{array}$ & $2.1 \pm 0.8(1.4-7)$ & 0.529 \\
\hline $\begin{array}{l}\text { Time to first oral intake } \\
\text { (range; d) } \\
\text { Postoperative } \\
\text { complications }(\mathrm{n} ; \%)\end{array}$ & $\begin{array}{l}2.6 \pm 1.1 \\
(1.9-9)\end{array}$ & $2.4 \pm 1.0(1.6-8)$ & 0.389 \\
\hline $\begin{array}{l}\text { Duodenal stump/ } \\
\text { anastomotic leakage }\end{array}$ & $3(4.9)$ & $3(4.4)$ & 1.000 \\
\hline $\begin{array}{l}\text { Intestinal } \\
\text { obstruction }\end{array}$ & $2(3.3)$ & I (I.5) & 0.602 \\
\hline Abdominal bleeding & I (I.6) & $4(5.9)$ & 0.369 \\
\hline Abdominal infection & $3(4.9)$ & $4(5.9)$ & 1.000 \\
\hline Lung infection & $2(3.3)$ & $0(0)$ & 0.222 \\
\hline Incision infection & $5(8.2)$ & $4(5.9)$ & 0.735 \\
\hline High fever & $4(6.6)$ & $2(2.9)$ & 0.421 \\
\hline $\begin{array}{l}\text { Abnormal routine } \\
\text { blood tests }\end{array}$ & $2(3.3)$ & $0(0)$ & 0.222 \\
\hline $\begin{array}{l}\text { Abnormal liver } \\
\text { function tests }\end{array}$ & $0(0)$ & I (I.5) & 1.000 \\
\hline $\begin{array}{l}\text { Abnormal renal } \\
\text { function tests }\end{array}$ & $0(0)$ & $0(0)$ & $\mathrm{N} / \mathrm{A}$ \\
\hline Allergic reaction & I (I.6) & $0(0)$ & 0.473 \\
\hline Neurotoxicity & $0(0)$ & $0(0)$ & $\mathrm{N} / \mathrm{A}$ \\
\hline Re-operation (n,\%) & $2(3.3)$ & $2(2.9)$ & 1.000 \\
\hline $\begin{array}{l}\text { Perioperative death } \\
(\mathrm{n}, \%)\end{array}$ & $0(0)$ & $0(0)$ & N/A \\
\hline $\begin{array}{l}\text { Postoperative hospital } \\
\text { stay (range; } d \text { ) }\end{array}$ & $\begin{array}{l}7.7 \pm 1.5 \\
(5-14)\end{array}$ & $7.5 \pm 1.3(6-12)$ & 0.423 \\
\hline
\end{tabular}

Notes: HIPEC, hyperthermic intraperitoneal chemotherapy. Abnormal routine blood tests refer to peripheral blood leukocyte counts $<3500 / \mathrm{mm}^{3}$ or platelet counts $<80,000 / \mathrm{mm}^{3}$ Abnormal liver function tests refer to serum bilirubin level $>3$ or liver enzymes $>3$ times ULN. Abnormal renal function tests refer to serum creatinine levels $>1.5 \mathrm{mg} / \mathrm{dl}$.

\section{Survival Outcomes}

Follow-up time lasted $33.1 \pm 2.1(20-42)$ months in the HIPEC group and $32.6 \pm 5.1(18-42)$ months in the nonHIPEC group ( $p=0.641)$. A total of $54(88.5 \%)$ HIPEC and $60(88.2 \%)$ non-HIPEC patients underwent postoperative adjuvant chemotherapy (oxaliplatin $130 \mathrm{mg} / \mathrm{m}^{2}$, d1; capecitabine $1000 \mathrm{mg} / \mathrm{m}^{2}, \mathrm{~d} 1-\mathrm{d} 14$, repeated every three weeks, 6 cycles). During the follow-up period, peritoneal cavity recurrence occurred in 3 (4.9\%) HIPEC and 12 (17.6\%) non-HIPEC patients $(p=0.029)$. Table 3 details that the mean time interval from surgery to peritoneal cavity recurrence was longer in HIPEC as compared to non-HIPEC patients $(25.4 \pm 4.2$ vs $22.1 \pm 5.7$ months, $p<0.001)$. The estimated illness-specific 3-year DFS rate was $89.4 \%$ in
Table 3 Survival Outcomes

\begin{tabular}{|c|c|c|c|}
\hline Variables & $\begin{array}{l}\text { HIPEC } \\
\text { Group } \\
(n=6 I)\end{array}$ & $\begin{array}{l}\text { Non-HIPEC } \\
\text { Group }(n=68)\end{array}$ & $p$ \\
\hline $\begin{array}{l}\text { Postoperative } \\
\text { chemotherapy (\%) }\end{array}$ & $54(88.5)$ & $60(88.2)$ & 1.000 \\
\hline $\begin{array}{l}\text { Peritoneal cavity } \\
\text { recurrence (\%) }\end{array}$ & $3(4.9)$ & $12(17.6)$ & 0.029 \\
\hline $\begin{array}{l}\text { Time interval } \\
\text { (range; mo) }\end{array}$ & $\begin{array}{l}25.4 \pm 4.2 \\
(20-30)\end{array}$ & $22.1 \pm 5.7(10-28)$ & $<0.001$ \\
\hline
\end{tabular}

Notes: HIPEC, hyperthermic intraperitoneal chemotherapy. Time interval refers to time from surgery to peritoneal cavity recurrence.

HIPEC and $73.9 \%$ in non-HIPEC patients $(\mathrm{HR}=0.376$, 95\% CI 0.166-0.852, $p=0.031$ ) (Figure 1A). Figure 1B details the estimated illness-specific 3-year OS rate was $89.4 \%$ in HIPEC and $84.3 \%$ in non-HIPEC patients $(\mathrm{HR}=0.605,95 \%$ CI $0.212-1.726, p=0.360)$.

\section{Discussion}

Prior studies have reported the recurrence rate for gastric cancer after radical surgery to be $30-50 \%$; peritoneal recurrence was also reported to be seen in $10-46 \%$ of patients after radical gastrectomy. ${ }^{3,11}$ Patients with peritoneal recurrence usually have a poor prognosis and a survival time of less than 5 months. Intravenous chemotherapy was found to neither significantly lower the rate of peritoneal recurrence nor improve prognosis for patients with peritoneal gastric cancer recurrence. ${ }^{6,12}$ It is thus urgent to establish treatment methods utilizing efficacious drugs.

Due to the plasma-peritoneal barrier, most intravenous chemotherapeutic agents do not remain in sufficient contact with lesions. Intraperitoneal perfusion chemotherapy has therefore emerged as an alternative treatment regimen. HIPEC was initially reported for treatment of peritoneal tumors in $1980 .{ }^{13}$ Compared with intravenous chemotherapy, HIPEC has significant advantages - notably the relative ease of attaining higher drug concentrations and a lower incidence of side effects - with proven beneficial effects in the treatment of gastric, colorectal, ovarian and other cancers. ${ }^{6,14-16}$

To date, a number of studies have confirmed the advantages of cytoreductive surgery (CRS) in combination with HIPEC for gastric cancer treatment. Cisplatin combined with 5-fluorouracil and mitomycin $\mathrm{C}$ has been the most widely studied HIPEC regimen. Yang et $\mathrm{al}^{16}$ reported that CRS and HIPEC in combination with mitomycin C $30 \mathrm{mg}$ 
A

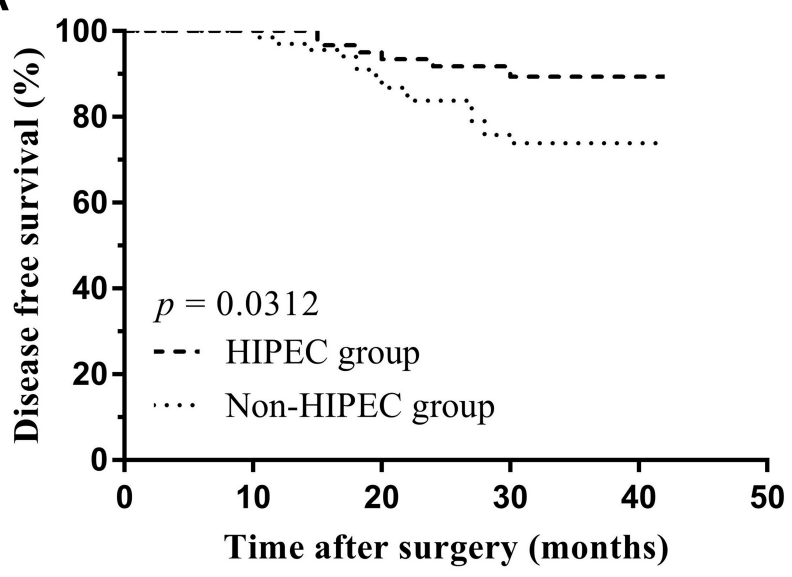

B

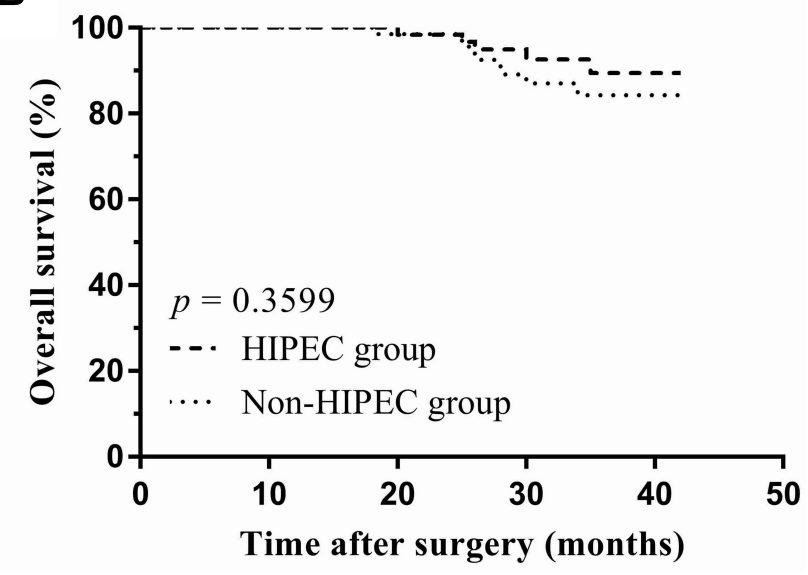

Figure I Illness-specific DFS (A) and OS (B).

and cisplatin $120 \mathrm{mg}$ improved survival (6.5 months in the CRS group vs 11.0 months in the CRS and HIPEC group; $p=0.046)$ while maintaining acceptable morbidity $(11.7 \%$ in the CRS group vs $14.7 \%$ in the CRS + HIPEC group; $p=0.839$ ). Murata et $\mathrm{al}^{17}$ also reported that 5-fluorouracil combined with cisplatin and mitomycin $\mathrm{C}$ may be an optimal HIPEC regimen for gastric cancer treatment. A number of scholars, however, have expressed opposite views. Ye et $\mathrm{al}^{18}$ reported that $21.3 \%$ (10/47) of patients in a cisplatin and HIPEC treatment group suffered acute kidney injury while two patients developed acute renal failure. Most importantly, long-term survival benefits were not found.

As third-generation platinum drugs, lobaplatin exhibits fewer side effects and has stronger anticancer activity when compared to other medications. $\mathrm{Li}$ et $\mathrm{al}^{9}$ reported that lobaplatin affects human BGC-823 cell survival by inducing apoptosis via the activation of cleaved caspase- 3 and $\mathrm{Bax}$, thus downregulating $\mathrm{Bcl}-2$. Hua et $\mathrm{al}^{19}$ reported that cyclin E1 and CDK2 levels were significantly increased, while cyclin B1 levels were markedly decreased, in SGC-7901 cells $(p<0.05)$; greater quantities of S-phase cells were observed when compared with controls $(60.03 \pm 1.25$ vs $18.69 \pm 0.96 \% ; p<0.05)$. Another study[8] reported that lobaplatin exhibited significant activity against cisplatin-resistant human ovarian and testicular carcinoma xenografts in vivo and that there was no cross-resistance to cisplatin in a 10 -fold cisplatin-resistant testicular carcinoma cell line (only weak cross-resistance in a 20-fold cisplatin-resistant ovarian carcinoma cell line was noted). Lobaplatin exhibits good antitumor activity not only in vivo but also in vitro. Huang et $\mathrm{al}^{20}$ reported that patients suffering malignant pleural effusion or ascites treated with lobaplatin likewise experienced more encouraging outcomes. In addition, Peng et $\mathrm{al}^{21}$ reported that a 73-year-old advanced gastric cancer patient suffering brain metastases was effectively treated by left gastric arterial and internal carotid arterial infusions of tegafur, epirubicin and lobaplatin.

Studies evaluating the efficacy of lobaplatin with HIPEC in the prevention of gastric cancer peritoneal metastases are scarce. Here, we found that postoperative complications, including duodenal stump or anastomotic leakage, abdominal bleeding, abdominal infection, and abnormal blood test results were not significantly increased by one-time HIPEC treatment immediately after surgery. These findings were in agreement with outcomes of intraoperative intraperitoneal perfusion chemotherapy with lobaplatin for colorectal cancer reported by Zhou HT. ${ }^{22}$ We additionally found that the peritoneal cavity recurrence rate was significantly decreased (4.9\% vs. $17.6 \% ; p=0.029)$ in HIPEC patients. Although we did not find an increased estimated illness-specific 3-year OS rate $(89.4 \%$ in HIPEC vs $84.3 \%$ in non-HIPEC groups; $p=0.355)$, we did find an increased estimated illnessspecific 3-year DFS rate $(89.4 \%$ in HIPEC vs $73.9 \%$ in nonHIPEC groups; $p=0.031)$. Whether follow-up time or sample size affects OS outcome, however, remains to be further studied.

Although this was a retrospective cohort study and selection bias was inevitable, the data of all enrolled patients were accurate and complete. We have every reason to believe in the reliability of our results. Our future work will focus on establishing ideal lobaplatin dosages and timeframes for prophylactic HIPEC treatment for advanced gastric cancer patients. Confirmatory randomized controlled trials would likewise be of great benefit. 


\section{Conclusions}

Lobaplatin in prophylactic HIPEC is safe in the setting of advanced gastric cancer and in patients previously treated with radical resection. This therapeutic regimen can effectively improve illness-specific 3-year DFS.

\section{Acknowledgments}

This work was supported by Wu Jieping Medical Foundation (2017-029-ZZ).

\section{Disclosure}

The authors have no conflicts of interest to declare.

\section{References}

1. Chen R, Zheng RS, Zhang SW, et al. Analysis of incidence and mortality of esophageal cancer in China, 2015. Zhonghua Yu Fang Yi Xиe Za Zhi. 2019;53(11):1094-1097. doi:10.3760/cma.j.issn.02539624.2019.11.004.

2. Wei J, Wu ND, Liu BR. Regional but fatal: intraperitoneal metastasis in gastric cancer. World J Gastroenterol. 2016;22(33):7478-7485. doi:10.3748/wjg.v22.i33.7478.

3. Macrì A, Morabito F. The use of intraperitoneal chemotherapy for gastric malignancies. Expert Rev Anticancer Ther. 2019;19 (10):879-888. doi:10.1080/14737140.2019.1671189.

4. Kobayashi D, Kodera Y. Intraperitoneal chemotherapy for gastric cancer with peritoneal metastasis. Gastric Cancer. 2017;20(Suppl 1):111-121. doi:10.1007/s10120-016-0662-9.

5. Kurtz F, Struller F, Horvath P, et al. Feasibility, safety, and efficacy of pressurized intraperitoneal aerosol chemotherapy (PIPAC) for peritoneal metastasis: a registry study. Gastroenterol Res Pract. 2018;2018:2743985. doi:10.1155/2018/2743985.

6. Shinkai M, Imano M, Chiba $\mathrm{Y}$, et al. Intraperitoneal and systemic chemotherapy for patients with gastric cancer with peritoneal metastasis: a phase ii trial. Anticancer Res. 2018;38(10):5975-5981. doi:10.21873/anticanres.12945.

7. Yang XJ, Huang CQ, Suo T, et al. Cytoreductive surgery and hyperthermic intraperitoneal chemotherapy improves survival of patients with peritoneal carcinomatosis from gastric cancer: final results of a Phase III randomized clinical trial. Ann Surg Oncol. 2011;18(6):1575-1581. doi:10.1245/s10434-011-1631-5.

8. Harstrick A, Bokemeyer C, Scharnofkse M, et al. Preclinical activity of a new platinum analogue, lobaplatin, in cisplatin-sensitive and resistant human testicular, ovarian, and gastric carcinoma cell lines. Cancer Chemother Pharmacol. 1993;33(1):43-47. doi:10.1007/BF 00686021.
9. Li Y, Liu B, Yang F, et al. Lobaplatin induces BGC-823 human gastric carcinoma cell apoptosis via ROS-mitochondrial apoptotic pathway and impairs cell migration and invasion. Biomed Pharmacother. 2016;83:1239-1246. doi:10.1016/j.biopha.2016.08. 053.

10. Yin CY, Lin XL, Tian L, et al. Lobaplatin inhibits growth of gastric cancer cells by inducing apoptosis. World J Gastroenterol. 2014;20 (46):17426-17433. doi:10.3748/wjg.v20.i46.17426.

11. Sugarbaker PH. Peritoneal metastases from gastrointestinal cancer. Curr Oncol Rep. 2018;20(8):62. doi:10.1007/s11912-018-0703-0.

12. Coccolini F, Fugazzola P, Ansaloni L, et al. Advanced gastric cancer: the value of systemic and intraperitoneal chemotherapy. Acta Biomed. 2018;89(8-S):104-109. doi:10.23750/abm.v89i8-S.7904.

13. Stehlin JS Jr, Greeff PJ, Giovanella BC, et al. Dramatic response of cancer to localized hyperthermia. N Y State J Med. 1980;80(1):70-72.

14. Hornung M, Werner JM, Schlitt HJ. Applications of hyperthermic intraperitoneal chemotherapy for metastatic colorectal cancer. Expert Rev Anticancer Ther. 2017;17(9):841-850. doi:10.1080/14737140. 2017.1357470.

15. van Driel WJ, Koole SN, Sikorska K, et al. Hyperthermic intraperitoneal chemotherapy in ovarian cancer. $N$ Engl J Med. 2018;378 (3):230-240. doi:10.1056/NEJMoa1708618.

16. Russell MC, Staley CA. Cytoreductive surgery and hyperthermic intraperitoneal chemotherapy for malignant peritoneal mesothelioma. J Oncol Pract. 2016;12(10):938-939. doi:10.1200/JOP.2016.016584.

17. Murata S, Yamamoto H, Naitoh H, et al. Feasibility and safety of hyperthermic intraperitoneal chemotherapy using 5-fluorouracil combined with cisplatin and mitomycin $\mathrm{C}$ in patients undergoing gastrectomy for advanced gastric cancer. J Surg Oncol. 2017;116 (8):1159-1165. doi:10.1002/jso.24771.

18. Ye J, Ren Y, Wei Z, et al. Nephrotoxicity and long-term survival investigations for patients with peritoneal carcinomatosis using hyperthermic intraperitoneal chemotherapy with cisplatin: a retrospective cohort study. Surg Oncol. 2018;27(3):456-461. doi:10.1016/j.suronc.2018.05.025.

19. Hua S, Kong X, Chen B, et al. Anticancer mechanism of lobaplatin as monotherapy and in combination with paclitaxel in human gastric cancer. Curr Mol Pharmacol. 2018;11(4):316-325. doi:10.2174/ 1874467211666180813095050 .

20. Huang XE, Wei GL, Huo JG, et al. Intrapleural or intraperitoneal lobaplatin for treatment of patients with malignant pleural effusion or ascites. Asian Pac J Cancer Prev. 2013;14(4):2611-2614. doi:10.73 14/apjcp.2013.14.4.2611.

21. Peng $\mathrm{Z}, \mathrm{Xu} \mathrm{S}, \mathrm{Li} \mathrm{H}$, et al. Advanced gastric cancer with brain metastasis effectively treated by arterial infusion chemotherapy: a case report. Oncol Lett. 2014;7(2):449-451. doi:10.3892/ol.2013. 1699.

22. Zhou HT, Jiang J, Guan X, et al. The short-term effect analysis of intraoperative intraperitoneal perfusion chemotherapy with lobaplatin for colorectal cancer. $J$ BUON. 2019;24(2):442-448.

\section{Publish your work in this journal}

Cancer Management and Research is an international, peer-reviewed open access journal focusing on cancer research and the optimal use of preventative and integrated treatment interventions to achieve improved outcomes, enhanced survival and quality of life for the cancer patient.
The manuscript management system is completely online and includes a very quick and fair peer-review system, which is all easy to use Visit http://www.dovepress.com/testimonials.php to read real quotes from published authors. 